\title{
Fluoxetine regulates the expression of neurotrophic/growth factors and glucose metabolism in astrocytes
}

\author{
Igor Allaman • Hubert Fiumelli • Pierre J. Magistretti • \\ Jean-Luc Martin
}

Received: 7 September 2010 / Accepted: 17 January 2011 / Published online: 8 February 2011

(C) Springer-Verlag 2011

\begin{abstract}
Rationale The pharmacological actions of most antidepressants are ascribed to the modulation of serotonergic and/or noradrenergic transmission in the brain. During therapeutic treatment for major depression, fluoxetine, one of the most commonly prescribed selective serotonin reuptake inhibitor (SSRI) antidepressants, accumulates in the brain, suggesting that fluoxetine may interact with additional targets. In this context, there is increasing evidence that astrocytes are involved in the pathophysiology of major depression.

Objectives The aim of this study was to examine the effects of fluoxetine on the expression of neurotrophic/growth factors that have antidepressant properties and on glucose metabolism in cultured cortical astrocytes.

Results Treatment of astrocytes with fluoxetine and paroxetine, another SSRI antidepressant, upregulated brainderived neurotrophic factor (BDNF), vascular endothelial growth factor (VEGF), and VGF mRNA expression. In contrast, the tricyclic antidepressants desipramine and imipramine did not affect the expression of these neurotrophic/growth factors. Analysis of the effects of fluoxetine
\end{abstract}

\author{
I. Allaman · P. J. Magistretti \\ Laboratory of Neuroenergetics and Cellular Dynamics, \\ Brain Mind Institute, \\ Ecole Polytechnique Fédérale de Lausanne (EPFL), \\ Lausanne CH-1015, Switzerland \\ H. Fiumelli $\cdot$ J.-L. Martin $(\bowtie)$ \\ Department of Physiology, University of Lausanne, \\ Rue du Bugnon 7, \\ 1005 Lausanne, Switzerland \\ e-mail: Jean-Luc.Martin@unil.ch \\ P. J. Magistretti $\cdot$ J.-L. Martin \\ Department of Psychiatry-CHUV, \\ Center for Psychiatric Neuroscience, \\ 1008 Prilly-Lausanne, Switzerland
}

on glucose metabolism revealed that fluoxetine reduces glycogen levels and increases glucose utilization and lactate release by astrocytes. Similar data were obtained with paroxetine, whereas imipramine and desipramine did not regulate glucose metabolism in this glial cell population. Our results also indicate that the effects of fluoxetine and paroxetine on glucose utilization, lactate release, and expression of BDNF, VEGF, and VGF are not mediated by serotonin-dependent mechanisms.

Conclusions These data suggest that, by increasing the expression of specific astrocyte-derived neurotrophic factors and lactate release from astrocytes, fluoxetine may contribute to normalize the trophic and metabolic support to neurons in major depression.

Keywords Antidepressants · Growth factors · Glia . Serotonin $\cdot$ Lactate $\cdot$ Glycogen

\section{Introduction}

Although pharmacological treatment of major depressive disorder has been available for over 50 years, the cellular and molecular mechanisms underlying antidepressant treatment remain largely unknown. Most of the antidepressants available today inhibit the reuptake or breakdown of serotonin, noradrenaline, or both in the brain. However, elevation of the extracellular concentration of these monoamines, which occurs rapidly, does not explain the time lag of several weeks to months that is required before a therapeutic response is achieved (Berton and Nestler 2006; Wong and Licinio 2004).

Selective serotonin reuptake inhibitors (SSRIs) are the most commonly prescribed drugs for the treatment of depression. Among SSRIs, fluoxetine is widely used to 
treat depression, and its biochemical and pharmacological properties have been studied extensively in animals and humans (Wong et al. 2005). During therapeutic treatment for major depression, fluoxetine accumulates in the brain, and fluoxetine concentrations in the $1-$ to $25-\mu \mathrm{M}$ range have been measured by fluorine magnetic resonance spectroscopy (Bolo et al. 2000; Henry et al. 2005). Because fluoxetine inhibits serotonin uptake in nerve endings with a $K_{\mathrm{i}}$ value of $0.07 \mu \mathrm{M}$ (Wong et al. 2005), the brain concentration of fluoxetine is approximately $15-350$ times higher than its binding affinity for serotonin transporters, suggesting that fluoxetine may interact with additional targets, including neurotransmitter- and voltage-gated ion channels (Bianchi 2008; Furutani et al. 2009).

There is increasing evidence indicating that glial cells are involved in the neuropathology of major depression. Indeed, post-mortem studies of depressed patients have revealed a reduced number and an altered morphology of glial cells in several cortical regions including the prefrontal and cingulate areas (Cotter et al. 2002; Ongur et al. 1998; Rajkowska et al. 1999). The decreases in glial cell density are accompanied by a reduction of astrocytic markers such as glial fibrillary acidic protein, glial high-affinity glutamate transporters, and glutamine synthetase in specific areas of the cerebral cortex from individuals with major depressive disorder (Choudary et al. 2005; Si et al. 2004), suggesting that astrocyte dysfunction may contribute to the pathophysiology of major depression. Preclinical studies have recently shown that glial cell loss in the rat prefrontal cortex is sufficient to induce depressive-like behaviors (Banasr and Duman 2008). Moreover, administration of fluoxetine reverses the inhibition of glial cell proliferation in the medial prefrontal cortex of rats subjected to chronic psychosocial stress (Czeh et al. 2006).

The possible contribution of astrocytic dysfunction to major depression and the reversal of stress-induced inhibition of gliogenesis by fluoxetine led us to hypothesize that fluoxetine may exert its beneficial effects by acting on astrocytes.

Although the concept of astrocytes as simple supportive cells for neurons has been widely accepted for decades, astrocytes are increasingly recognized to play important roles in neuronal development, neurotransmission, and synaptic plasticity (Allen and Barres 2005; Slezak and Pfrieger 2003; Perea et al. 2009; Halassa and Haydon 2010; Barker and Ullian 2010). Astrocytes regulate neuronal survival, neurite outgrowth, and synaptogenesis, and also provide trophic, structural, and metabolic support to neurons during development (Wang and Bordey 2008). In this regard, astrocytes synthesize and release different trophic factors among which brain-derived neurotrophic factor (BDNF), fibroblast growth factor 2 (FGF-2), insulinlike growth factor 1 (IGF-1), and glial cell line-derived neurotrophic factor (GDNF) have been shown to be regulated by chronic antidepressant treatment in the hippocampus (Nibuya et al. 1995; Mallei et al. 2002; Khawaja et al. 2004; Hisaoka et al. 2007) and to induce antidepressant-like effects in behavioral models of depression (Shirayama et al. 2002; Hoshaw et al. 2005; Turner et al. 2008).

In addition to trophic factors, astrocytes provide essential energy substrates for neurons to sustain their normal function and cellular integrity. Although neurons can import glucose directly from the extracellular space, there is increasing evidence that glucose is also taken up by astrocytes, metabolized glycolytically to lactate which is then released extracellularly to be used by neurons as an energy substrate to sustain their activity (Rouach et al. 2008; Pellerin et al. 2007).

The aim of this study was to determine whether astrocytes are a target of fluoxetine by examining the effects of fluoxetine on the expression of neurotrophic/ growth factors that have antidepressant properties and on glucose metabolism in cortical astrocytes. We also compared the effects of fluoxetine with those of the SSRI paroxetine and the tricyclic antidepressants desipramine and imipramine.

\section{Materials and methods}

\section{Reagents}

Deoxy-D-glucose, 2-[1,2- $\left.{ }^{3} \mathrm{H}(\mathrm{N})\right]$ (specific activity, 30$60 \mathrm{Ci} / \mathrm{mmol})\left(\left[{ }^{3} \mathrm{H}\right]-2-\mathrm{DG}\right)$ was obtained from ANAWA (Wangen, Switzerland). Enzymes for glycogen and lactate release assays as well as NAD, NADP, and ATP were purchased from Roche Diagnostics (Rotkreuz, Switzerland). Fetal calf serum (FCS) was purchased from Bioconcept (Allschwil, Switzerland). All other chemicals, including Dulbecco's modified Eagle's mediums (DMEM), fluoxetine, paroxetine, imipramine, desipramine, and serotonin were obtained from Sigma-Aldrich (Buchs, Switzerland). All reagents used to reverse transcribe RNA and to amplify DNA were purchased from Applied Biosystems (Rotkreuz, Switzerland).

Cortical astrocyte culture

Primary cultures of cerebral cortical astrocytes were prepared from 1- to 2-day-old Swiss albino mice (OF1, Charles River Laboratories, L'Arbresle, France), as previously described (Allaman et al. 2010). Briefly, brains were removed aseptically from the skull, meninges were excised carefully, and the neocortices were dissected. Cells were dissociated by passages through needles of increasing 
gauges (16-, 19-, and 25-gauge) with a 10-mL syringe and seeded on polyornithine-coated dishes $(35 \mathrm{~mm})$ in DMEM (D7777) containing $25 \mathrm{mM}$ glucose and supplemented with $44 \mathrm{mM} \mathrm{NaHCO}, 10 \mathrm{~mL} / \mathrm{L}$ of a $100 \times$ antibiotic-antimycotic solution (Invitrogen, Basel, Switzerland), and $10 \%$ FCS. Cells were incubated at $37^{\circ} \mathrm{C}$ in an atmosphere containing 5\% $\mathrm{CO}_{2}-95 \%$ air. The culture medium was renewed 5 days after seeding and, subsequently, twice a week. Twenty-one-day-old confluent cultures were used for all experiments. Using this culture procedure, $>90 \%$ of the cells were immunoreactive for glial fibrillary acidic protein.

\section{Exposure to antidepressants}

During all treatments, primary cultures of astrocytes were maintained at $37^{\circ} \mathrm{C}$ in an atmosphere containing $5 \% \mathrm{CO}_{2}-$ 95\% air. Twenty-four hours before exposure to antidepressants, the culture medium was removed, and astrocytes were incubated in serum-free DMEM (D5030) supplemented with $5 \mathrm{mM}$ glucose, $44 \mathrm{mM} \mathrm{NaHCO}_{3}$, and $10 \mathrm{~mL} / \mathrm{L}$ of an $100 \times$ antibiotic-antimycotic solution (Invitrogen) $\left(\mathrm{DMEM}_{5}\right)$. Cortical astrocytes were then exposed to the different antidepressants or serotonin for $24 \mathrm{~h}$.

\section{Quantitative PCR analysis}

At the end of the stimulation, cultured cortical astrocytes were washed twice with $4 \mathrm{~mL}$ of ice-cold phosphatebuffered saline (PBS), and total RNA was isolated using the RNeasy Plus Mini Kit (Qiagen, Hombrechtikon, Switzerland). The concentration of RNA was determined using a NanoDrop ND-1000 spectrophotometer (Fisher Scientific, Wohlen, Switzerland). RNA samples (800 ng) were then reverse transcribed into first-strand cDNA with the TaqMan ${ }^{\circledR}$ reverse transcription reagents and random hexamers, according to the manufacturer's protocol (Applied Biosystems). Using the Power SYBR Green PCR Master Mix (Applied Biosystems) and different sets of primers (Table 1) designed with the Primer Express 3.0 software (Applied
Biosystems), 1/25 of the resulting cDNA was quantitatively amplified by real-time PCR with the 7900HT Fast RealTime PCR system (Applied Biosystems). The specificity of PCR amplification for each set of primers was checked by the presence of a single sharp peak in the melting curve analysis. Relative mRNA levels were analyzed with qBase software (Jan Hellemans and Jo Vandesompele, Center for Medical Genetics, Ghent University Hospital) using a delta$C_{\mathrm{T}}\left(\Delta \Delta C_{\mathrm{t}}\right)$ relative quantification model (Livak and Schmittgen, 2001) with TATA box-binding protein (TBP) and $\beta$-glucuronidase as reference genes. For each mRNA transcript, data were expressed as fold changes relative to untreated control cultures.

\section{BDNF ELISA}

After treatment with fluoxetine or paroxetine, cultured cortical astrocytes were washed once with $4 \mathrm{~mL}$ of icecold PBS, and cells were harvested in $150 \mu \mathrm{L}$ lysis buffer (137 mM NaCl; 20 mM Tris-HCl, pH 8.0; 1\% NP-40; 10\% glycerol) containing protease (Complete ${ }^{\mathrm{TM}}$, Roche Diagnostic) and phosphatase (Sigma-Aldrich) inhibitor cocktails. A $100-\mu \mathrm{L}$ aliquot was used to determine BDNF cellular content using the BDNF $\mathrm{E}_{\max }{ }^{\circledR}$ Immunoassay System (Promega, Dübendorf, Switzerland), according to the manufacturer's instructions. Absolute values were determined from a standard curve. The protein content was measured in the remaining cell lysate with the BCA protein assay reagent kit (Pierce, Lausanne, Switzerland), and values were expressed as picograms of BDNF per milligram of protein.

\section{$\left[{ }^{3} \mathrm{H}\right]-2-\mathrm{DG}$ uptake}

$\left[{ }^{3} \mathrm{H}\right]-2-\mathrm{DG}$ uptake experiments were conducted as previously described (Allaman et al. 2010). After treatment with antidepressants or serotonin, $\left[{ }^{3} \mathrm{H}\right]-2-\mathrm{DG}$ assay was initiated by replacing the medium with $2 \mathrm{~mL}$ of $\mathrm{DMEM}_{5}$ containing $1 \mu \mathrm{Ci} / \mathrm{mL}\left[{ }^{3} \mathrm{H}\right]$-2-DG. The cells were incubated for an additional $20 \mathrm{~min}$ at $37^{\circ} \mathrm{C}$ in an atmosphere containing $5 \%$

Table 1 Primer sequences for quantitative PCR analysis

\begin{tabular}{llll}
\hline Gene & Sense primer & Antisense primer & Accession number \\
\hline B-glucuronidase & GGGCATTTGGAGGTGATTCA & TGCTCCATACTCGCTCTGGAT & NM_010368 \\
BDNF & AAAACCATAAGGACGCGGACTT & GAGGCTCCAAAGGCACTTGA & NM_007540 \\
FGF-2 & GCGACCCACACGTCAAACTA & GGTACCGGTTGGCACACAT & NM_008006 \\
GDNF & TGACTCCAATATGCCTGAAGATTATC & TCAGTCTTTTAATGGTGGCTTGAA & NM_010275 \\
IGF-1 & CCCGTCCCTATCGACAAACA & TTCCTGCACTTCCTCTACTTGTGT & NM_010512 \\
TBP & CAACAGCCTTCCACCTTATGC & CATTGGACTAAAGATGGGAATTCC & NM_013684 \\
VEGF & GCAGGCTGCTGTAACGATGA & TTGATCCGCATGATCTGCAT & NM_001025250 \\
VGF & CAGCCCGTTGGTCATGAAA & CTCCCAACCCCTGGATCAGT & NM_001039385 \\
\hline
\end{tabular}


$\mathrm{CO}_{2}-95 \%$ air. The uptake was terminated by collecting the culture medium (for lactate release assay, see below) and by washing the cells three times with $4 \mathrm{~mL}$ of ice-cold PBS. Cells were then lysed by the addition of $2 \mathrm{~mL}$ of $10 \mathrm{mM}$ $\mathrm{NaOH}$ containing $0.1 \%$ Triton X-100. Five hundredmicroliter aliquots, in duplicate, were assayed for radioactivity by liquid scintillation counting. Results, which represent the transporter-mediated glucose uptake and subsequent phosphorylation, were calculated by subtracting from total counts the portion that was not inhibited by the glucose transporter inhibitor cytochalasin $\mathrm{B}(25 \mu \mathrm{M})$ added 20 min prior to and along $\left[{ }^{3} \mathrm{H}\right]-2-\mathrm{DG}$ incubation. The medium used for $\left[{ }^{3} \mathrm{H}\right]-2-D G$ uptake was pre-equilibrated at $37^{\circ} \mathrm{C}$ in an atmosphere containing $5 \% \mathrm{CO}_{2}-95 \%$ air. The protein content was measured in the remaining lysate with the BCA protein assay reagent kit (Pierce) according to the manufacturer's instructions. [ $\left.{ }^{3} \mathrm{H}\right]-2-\mathrm{DG}$ uptake was expressed as fentomoles per milligram of protein.

\section{Lactate release}

Lactate released by astrocytes was determined as previously described (Allaman et al. 2010). Briefly, 100- $\mu \mathrm{L}$ aliquots of the culture medium used for $\left[{ }^{3} \mathrm{H}\right]-2-\mathrm{DG}$ incubation were mixed with $1 \mathrm{~mL}$ of glycine buffer $(0.2 \mathrm{mM}, \mathrm{pH} 10)$ containing $2 \mathrm{mg} / \mathrm{mL} \mathrm{NAD}$ and $7 \mathrm{U} / \mathrm{mL}$ lactate dehydrogenase and incubated at $40^{\circ} \mathrm{C}$ for $1 \mathrm{~h}$. After $20 \mathrm{~min}$ at room temperature, the amount of NADH produced was measured by fluorescence at $340 / 450 \mathrm{~nm}$ (excitation/emission) in a $200-\mu \mathrm{L}$ aliquot loaded on a 96-well plate using a spectrophotometer (Safire 2, TECAN, Männedorf, Switzerland), and absolute values of lactate were determined from a standard curve. Lactate release into the medium was expressed as nanomoles per milligram of protein.

\section{Glycogen assay}

At the end of the treatments, astrocytes were rinsed three times with ice-cold PBS and lysed by sonication in $1.5 \mathrm{~mL}$ of $30 \mathrm{mM} \mathrm{HCl}$. Glycogen content of the cell extract was determined enzymatically as previously described (Allaman et al. 2004). Briefly, two $100-\mu \mathrm{L}$ aliquots were sampled in duplicate. Acetate buffer, $300 \mu \mathrm{L}(0.1 \mathrm{M}, \mathrm{pH} 4.65)$, was added to the first aliquot, and $300 \mu \mathrm{L}$ of the same acetate buffer containing $1 \%(v / v)$ amyloglucosidase $(140 \mathrm{U} / \mathrm{mL})$ was added to the other. After incubation (30 $\mathrm{min}$ at room temperature), $2 \mathrm{~mL}$ of Tris-HCl buffer $(0.1 \mathrm{mM}$, pH 8.1) containing $3.3 \mathrm{mM} \mathrm{MgCl}, 0.2 \mathrm{mM}$ ATP, $25 \mu \mathrm{g} / \mathrm{mL}$ NADP, $0.7 \mathrm{U} / \mathrm{mL}$ hexokinase, and $0.35 \mathrm{U} / \mathrm{mL}$ glucose-6-phosphate dehydrogenase were added to the aliquots, and the mixture was incubated for $30 \mathrm{~min}$ at room temperature. The fluorescence of the NADPH formed was determined at $340 / 450 \mathrm{~nm}$ (excitation/emission) using a fluorometer and a glucose standard curve. The first aliquot provided the signal generated by glucose and glucose-6-phosphate, while the second aliquot corresponded to the signal generated by glycogen plus glucose and glucose-6-phosphate. The amount of glycogen was determined by the difference between the two signals. It is important to note that, hereafter, "1 mole of glycogen" represents 1 mole of glycosyl unit originating from glycogen. The protein content of the cell lysate was determined using the BCA protein assay reagent kit (Pierce), and the glycogen cell content was expressed as nanomoles per milligram of protein.

\section{Statistical analysis}

Data were analyzed for statistical significance with Student's $t$ test or by one-way ANOVA, followed either by Dunnett's or Bonferroni's post hoc test, using InStat 3.0 software (GraphPad, San Diego, CA).

\section{Results}

Among neurotrophic/growth factors that are synthesized by astrocytes, BDNF, FGF-2, IGF-1, and GDNF are regulated by antidepressant treatments (Nibuya et al. 1995; Mallei et al. 2002; Khawaja et al. 2004; Hisaoka et al. 2007) and produce antidepressant-like effects in behavioral models of depression (Shirayama et al. 2002; Hoshaw et al. 2005; Turner et al. 2008), suggesting that these neurotrophic/ growth factors may contribute to the therapeutic action of antidepressant treatment. On the basis of these observations, we examined whether fluoxetine, one of the most commonly prescribed antidepressants, regulates the expression of BDNF, FGF-2, IGF-1, and GDNF in cortical astrocytes. Quantitative PCR analysis revealed that treatment of cortical astrocytes with $10 \mu \mathrm{M}$ fluoxetine increased BDNF mRNA levels $(212.1 \pm 10.3 \%$ of the control), while IGF-1 and GDNF mRNA levels remained unchanged (Fig. 1). Levels of FGF-2 mRNA showed a tendency to increase with fluoxetine which was not, however, statistically significant (Fig. 1). In addition to BDNF, FGF-2, IGF1 , and GDNF, we investigated whether fluoxetine affects the expression of vascular endothelial growth factor (VEGF) and VGF, two growth factors that produce antidepressant-like effects in behavioral models of depression (Warner-Schmidt and Duman 2007, 2008; ThakkerVaria et al. 2007; Hunsberger et al. 2007). Exposure of cortical astrocytes to fluoxetine caused a marked enhancement of VEGF and VGF mRNA levels $(377.8 \pm 32.0 \%$ and $226.3 \pm 17.4 \%$ of controls, respectively; Fig. 1). Consistent with these data, paroxetine, another SSRI antidepressant, upregulated BDNF, VEGF, and VGF mRNA levels, without significantly affecting the expression levels of 


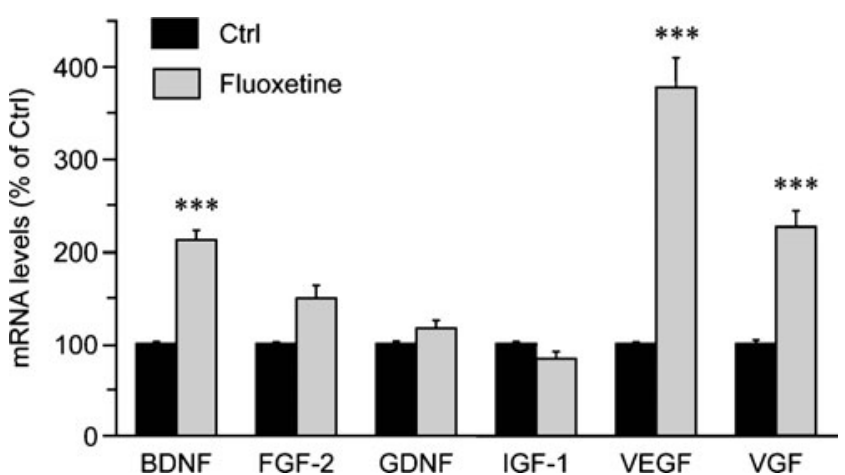

Fig. 1 Fluoxetine increases the expression of BDNF, VEGF, and VGF mRNAs in cortical astrocytes. Astrocytes were exposed to $10 \mu \mathrm{M}$ fluoxetine for $24 \mathrm{~h}$, and mRNA levels of BDNF, FGF-2, GDNF, IGF-1, VEGF, and VGF were analyzed by quantitative PCR. Results are expressed as percentages of control (Ctrl) values for each neurotrophic/growth factor and are the means \pm SEM of at least 37 determinations from 12 independent experiments. Data were statistically analyzed using ANOVA followed by Bonferroni's test. $* * * P<0.001$ versus $C$ trl

FGF-2, GDNF, and IGF-1 mRNAs (Fig. 2). The increase in BDNF mRNA levels by fluoxetine and paroxetine were confirmed at the protein level by ELISA. Thus, fluoxetine and paroxetine enhanced BDNF protein levels in cortical

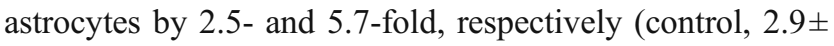
$0.2 \mathrm{pg} / \mathrm{mg}$ protein; fluoxetine, $7.2 \pm 0.2 \mathrm{pg} / \mathrm{mg}$ protein; and paroxetine, $16.5 \pm 2.3 \mathrm{pg} / \mathrm{mg}$ protein; mean $\pm \mathrm{SEM}$ of nine determinations from three independent experiments; $P<0.05$ between control and fluoxetine-treated groups and $P<0.01$ between control and paroxetine-treated groups by ANOVA followed by Dunnett's test). In contrast to the effects of the SSRIs fluoxetine and paroxetine, the tricyclic antidepressants desipramine and imipramine did not affect

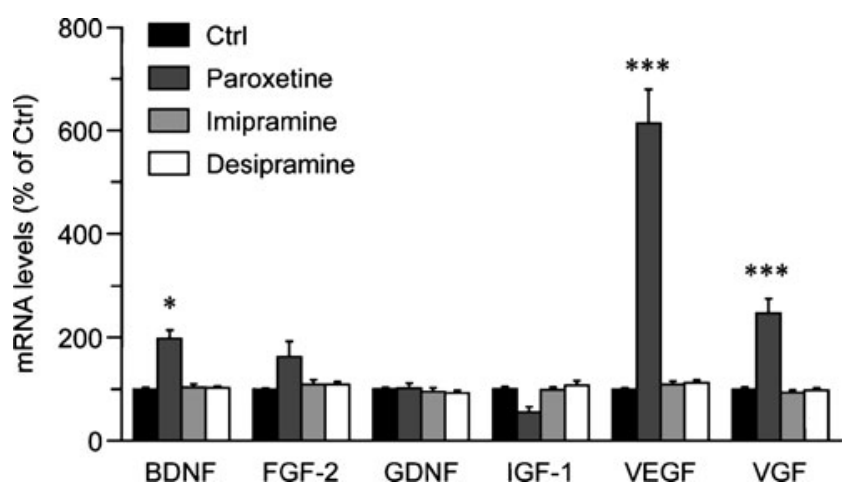

Fig. 2 Paroxetine, but not imipramine and desipramine, upregulates BDNF, VEGF, and VGF mRNA levels in cortical astrocytes. Astrocytes were treated with $(10 \mu \mathrm{M})$ paroxetine, imipramine, or desipramine for $24 \mathrm{~h}$, and mRNA levels of BDNF, FGF-2, GDNF, IGF-1, VEGF, and VGF were analyzed by quantitative PCR. Results are expressed as percentages of the control $(C t r l)$ value for each neurotrophic/growth factor and are the means \pm SEM of at least 14 determinations from 5 independent experiments. Data were statistically analyzed by ANOVA followed by Bonferroni's test. $* P<0.05$ versus $C$ trl, $* * * P<0.001$ versus $C t r l$ the expression of these neurotrophic/growth factors in cortical astrocytes (Fig. 2).

In addition to supplying neurotrophic/growth factors, there is ample evidence that astrocytes provide essential energy substrates to neurons (Magistretti 2008). In particular, it has been shown that glucose is taken up by astrocytes and metabolized glycolytically to lactate which is then released in the extracellular space and oxidized by neurons to meet part of their energy needs (Pellerin et al. 2007). These observations led us to examine whether fluoxetine alters the release of lactate from cortical astrocytes. Treatment of cortical astrocytes with fluoxetine resulted in an increased lactate release $(125.0 \pm 7.6 \%$ of the control; Fig. 3a). Similar data were obtained with paroxetine, while imipramine and desipramine did not affect lactate release from astrocytes (Fig. 3a). We next examined whether the increased release of lactate by fluoxetine was coupled with an enhancement of glucose utilization by astrocytes. Treatment of cortical astrocytes with fluoxetine resulted in an increased glucose utilization $(126.0 \pm 6.8 \%$ of the control), as shown by the stimulation of $\left[{ }^{3} \mathrm{H}\right]-2-\mathrm{DG}$ uptake by astrocytes (Fig. 3b). Consistent with the data from the lactate release experiments (Fig. 3a), paroxetine enhanced $\left[{ }^{3} \mathrm{H}\right]-2-\mathrm{DG}$ uptake, whereas the tricyclic antidepressants imipramine and desipramine had no significant effect on glucose utilization by astrocytes (Fig. 3b).

Glycogen is the major energy reserve of the brain and is localized almost exclusively in astrocytes (Magistretti et al. 1993; Brown and Ransom 2007). Compelling evidence indicates that mobilization of astrocyte glycogen can provide additional energy substrates for neurons when energy demand exceeds glucose supply (Brown and Ransom 2007). We therefore examined whether fluoxetine regulates glycogen levels in astrocytes. Our studies revealed that treatment of cortical astrocytes with fluoxetine and paroxetine decreased glycogen levels $(77.7 \pm 2.2 \%$ and $63.1 \pm 4.4 \%$ of the control, respectively), whereas neither imipramine nor desipramine altered glycogen metabolism (Fig. 3c). Reduction of glycogen levels by fluoxetine in astrocytes is consistent with previous observations (Zhang et al. 1993). Together, these results indicate that fluoxetine and paroxetine regulate glycogen levels, glucose utilization, and lactate release by cortical astrocytes (Fig. 3).

As SSRIs increase the extracellular level of serotonin within the synaptic cleft by inhibiting its reuptake into the presynaptic cell, we next examined whether the effects of fluoxetine on the expression of neurotrophic/growth factors and glucose metabolism in cortical astrocytes were mediated by serotonin. We addressed this issue by investigating whether regulation of glycogen levels, glucose utilization, lactate release, and expression of neurotrophic/growth factors by serotonin was similar to that by fluoxetine. Consistent with previous observations (Magistretti et al. 


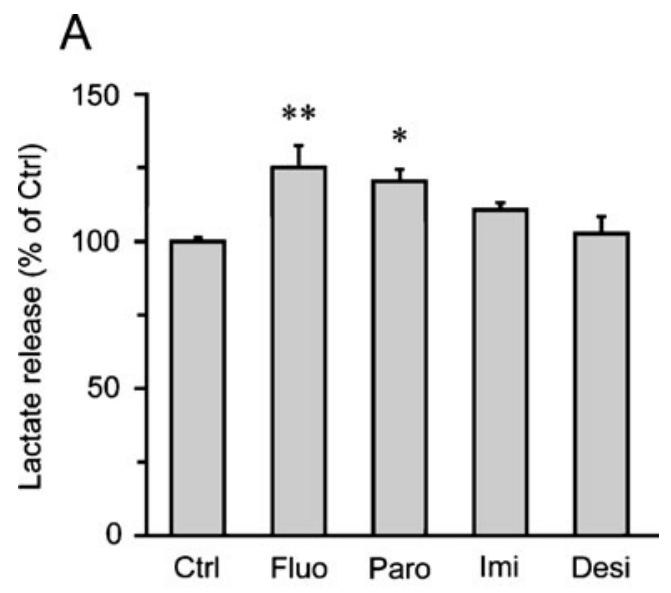

B
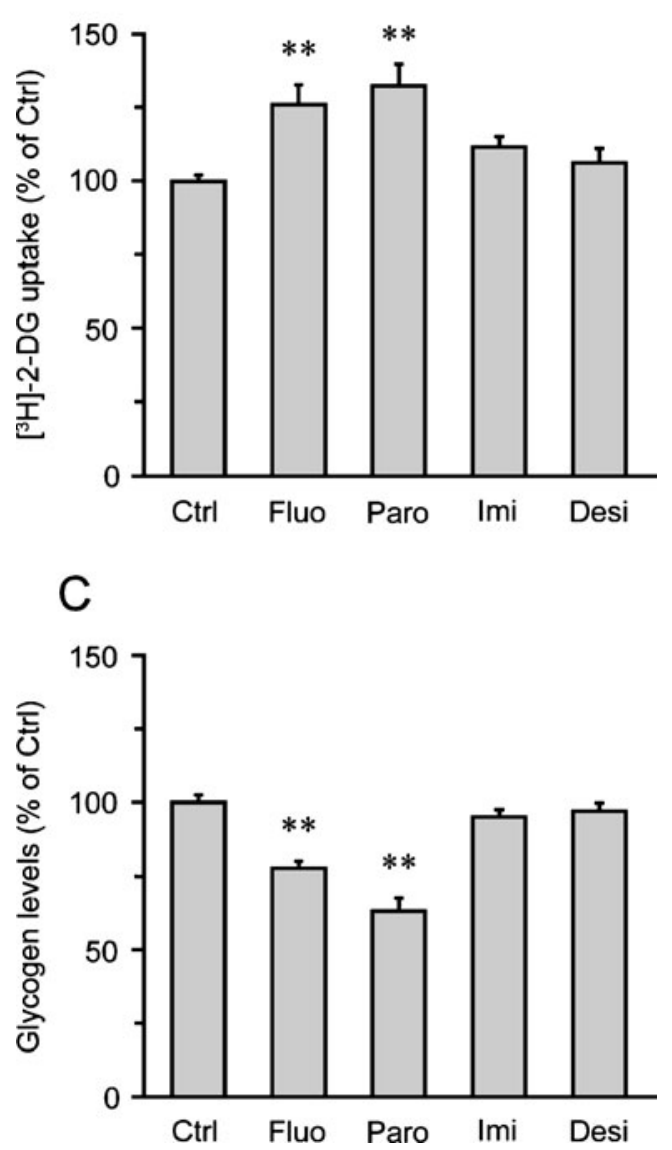

1983), stimulation of cortical astrocytes by serotonin resulted in reduced glycogen levels $(75.3 \pm 2.2 \%$ of the control, Fig. 4a). In contrast, serotonin did not affect $\left[{ }^{3} \mathrm{H}\right]-$ 2-DG uptake, lactate release, and levels of BDNF, FGF-2, GDNF, IGF-1, VEGF, and VGF mRNAs (Fig. 4b-d). These data indicate that the effects of fluoxetine and paroxetine on glucose utilization, lactate release, and the expression of BDNF, VEGF, and VGF mRNAs in cortical astrocytes are not mediated by serotonin-dependent mechanisms.
Fig. 3 Fluoxetine and paroxetine, but not imipramine and desipramine, regulate lactate release, glucose utilization, and glycogen levels in cortical astrocytes. Astrocytes were exposed to $(10 \mu \mathrm{M})$ fluoxetine (Fluo), paroxetine (Paro), imipramine (Imi), or desipramine (Desi) for $24 \mathrm{~h}$, and lactate release, glucose utilization, and glycogen levels were measured. a Lactate release. Results are expressed as percentages of the control (Ctrl) value $(1,922.0 \pm 95.4 \mathrm{nmol} / \mathrm{mg}$ prot $)$ and are the means \pm SEM of at least 11 determinations from 4 independent experiments. b Glucose utilization as determined using the $\left[{ }^{3} \mathrm{H}\right]-2-\mathrm{DG}$ uptake technique. Results are expressed as percentages of the Ctrl value $\left(336.2 \pm 14.3\right.$ fmol of $\left[{ }^{3} \mathrm{H}\right]-2-$ DG uptake/mg prot) and are the means \pm SEM of at least 11 determinations from 4 independent experiments. c Glycogen levels. Results are expressed as percentages of the $C t r l$ value $(60.9 \pm 4.1 \mathrm{nmol} / \mathrm{mg}$ prot$)$ and are the means \pm SEM of at least 9 determinations from 3 independent experiments. All data were statistically analyzed with ANOVA followed by Dunett's test. $* P<0.05$ versus $C$ trl, ${ }^{* *} P<0.01$ versus $C t r l$
A

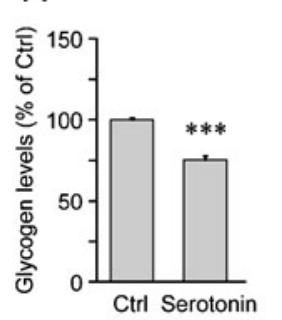

B
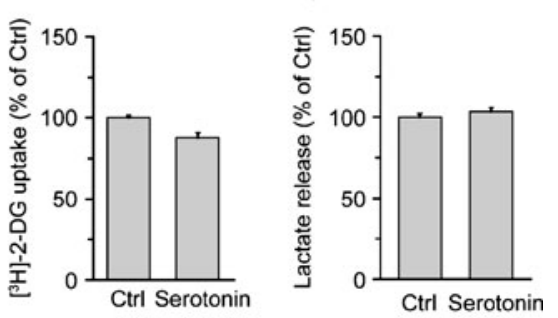

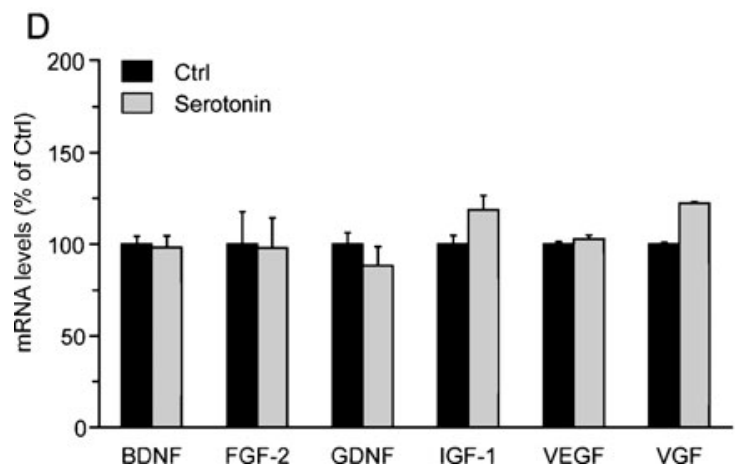

Fig. 4 Effects of serotonin on glucose metabolism and neurotrophic/ growth factor expression in cortical astrocytes. Astrocytes were exposed to $100 \mu \mathrm{M}$ serotonin for $24 \mathrm{~h}$, and glycogen levels, glucose utilization, lactate release, and expression of neurotrophic/growth factors were measured. a Glycogen levels. Results are expressed as percentages of the control $(C t r l)$ value $(45.0 \pm 1.7 \mathrm{nmol} / \mathrm{mg}$ prot $)$ and are the means \pm SEM of at least 8 determinations from 3 independent experiments. b Glucose utilization as determined using the $\left[{ }^{3} \mathrm{H}\right]-2-\mathrm{DG}$ uptake technique. Results are expressed as percentages of the Ctrl value $\left(253.3 \pm 15.4 \mathrm{fmol}\right.$ of $\left[{ }^{3} \mathrm{H}\right]-2-\mathrm{DG}$ uptake/mg prot) and are the means \pm SEM of 15 determinations from 5 independent experiments. $\mathbf{c}$ Lactate release. Results are expressed as percentages of the Ctrl value $(1,445.7 \pm 125.17 \mathrm{nmol} / \mathrm{mg}$ prot $)$ and are the means \pm SEM of 15 determinations from 5 independent experiments. d Analysis of BDNF, FGF-2, GDNF, IGF-1, VEGF, and VGF mRNA levels by quantitative PCR. Results are expressed as percentages of the Ctrl value for each neurotrophic/growth factor and are the means \pm SEM of 9 determinations from 3 independent experiments. Data shown in $\mathbf{a}, \mathbf{b}$ and $\mathbf{c}$ were statistically analyzed by ANOVA followed by $t$ test $(* * * P<0.0001)$. Data shown in $\mathbf{d}$ were statistically analyzed using ANOVA followed by Bonferroni's test (no significant differences between $\mathrm{Ctrl}$ and serotonin conditions) 


\section{Discussion}

Data from the current study indicate that fluoxetine and paroxetine increase the expression of BDNF, VEGF, and VGF; glucose utilization; and lactate release from cortical astrocytes by serotonin-independent mechanisms. In contrast, the tricyclic antidepressants desipramine and imipramine neither affect the expression of these neurotrophic/ growth factors nor glucose metabolism in this glial cell population.

In vivo imaging studies of patients with major depression have shown that the hippocampus and prefrontal cortex undergo selective volume reductions (Drevets 2000a; Bremner et al. 2002; Sheline 2003). Moreover, post-mortem histological analysis of the prefrontal cortex of patients suffering from major depressive disorder has demonstrated reductions in the number and density of glial cells and in the size of neuronal cell bodies, which may contribute to these volume reductions (Rajkowska and Miguel-Hidalgo 2007; Cotter et al. 2002; Ongur et al. 1998). Interestingly, decreases in glial cell density in the prefrontal cortex of depressed patients are accompanied by a reduction of astrocytic markers (Choudary et al. 2005; Si et al. 2004), suggesting that an astrocytic deficit may contribute to the etiology of major depression. In support of this hypothesis, glial ablation in the prefrontal cortex is sufficient to induce depressive-like behaviors (Banasr and Duman 2008).

Astrocytes have important functions that include the promotion of neuronal maturation, synapse formation, and neuronal survival during development, the regulation of angiogenesis, and the maintenance of a viable microenvironment for neurons (Wang and Bordey 2008). In this context, astrocytes provide neurotrophic/growth factors and energy substrates that are essential for neuronal survival and neurite outgrowth (Wang and Bordey 2008). Among neurotrophic/growth factors that we found to be expressed in cortical astrocytes, BDNF, VEGF, and VGF are upregulated by fluoxetine (Fig. 1).

BDNF regulates the survival and differentiation of specific subsets of neurons in the central and peripheral nervous systems (Jones et al. 1994; Lewin and Barde 1996). In the central nervous system, BDNF controls dendritic growth (McAllister et al. 1995, 1996) and provides trophic support to a variety of neurons including cortical and hippocampal neurons (Ghosh et al. 1994; Lindholm et al. 1996). These observations suggest that selective reductions in the volume of the prefrontal cortex and hippocampus of depressed patients may result from the reduced supply of BDNF. In support of this hypothesis, post-mortem analysis of brain tissue has revealed that the expression of BDNF is decreased in the hippocampus of depressed suicide victims compared to that of healthy controls (Chen et al. 2001; Dwivedi et al. 2003). Therefore, the increased expression of BDNF by fluoxetine in cortical astrocytes (Fig. 1) may contribute to block or reverse neuronal atrophy and cell loss observed in the prefrontal cortex of depressed patients.

VEGF was originally described as an endothelial cell mitogen and survival factor that regulates angiogenesis and vascular permeability (Ferrara et al. 2003). More recent studies have provided evidence that VEGF increases the proliferation of neuronal progenitors (Wada et al. 2006), stimulates adult neurogenesis (Jin et al. 2002), and promotes neurite outgrowth (Jin et al. 2006; Rosenstein et al. 2003; Khaibullina et al. 2004). In addition, VEGF has been shown to contribute to the actions of antidepressant treatment. Thus, chronic antidepressant administration increases VEGF expression in the hippocampus (WarnerSchmidt and Duman 2007), and infusion of VEGF into the lateral ventricles enhances neurogenesis and produces antidepressant responses in different animal models of depression (Warner-Schmidt and Duman 2007). Recent observations indicate that VEGF is required for the effects of fluoxetine in different behavioral paradigms and that chronic administration of fluoxetine increases VEGF expression in neurons and endothelial cells of the hippocampus (Greene et al. 2009). Interestingly, our data extend these observations by demonstrating that, in addition to neurons and endothelial cells, fluoxetine can also regulate VEGF expression in astrocytes (Fig. 1). In this context, it is of interest that the mood stabilizer lithium upregulates the expression of VEGF in cortical astrocytes (Guo et al. 2009). Because VEGF increases cell body diameter and neurite outgrowth from cortical neurons (Rosenstein et al. 2003) as well as astroglial proliferation (Krum et al. 2002), this suggests that upregulation of VEGF expression by fluoxetine in cortical astrocytes (Fig. 1) may contribute to reverse the structural changes in the prefrontal cortex of depressed patients.

VGF is a secreted neuropeptide that is involved in the regulation of energy balance and synaptic plasticity (Alder et al. 2003; Salton et al. 2000). More recently, VGF has been shown to induce antidepressant-like actions in rodents (Hunsberger et al. 2007; Thakker-Varia et al. 2007). Thus, local infusion of VGF into the midbrain or hippocampus produces antidepressant responses in several animal models of depression (Thakker-Varia et al. 2007; Hunsberger et al. 2007), and heterozygous $\mathrm{VGF}^{+/-}$mice exhibit an increased depression-like behavior (Hunsberger et al. 2007). There is also evidence that VGF is upregulated in the rodent hippocampus after manipulations that have antidepressantlike activity (Hunsberger et al. 2007; Thakker-Varia et al. 2007; Newton et al. 2003). Our data showing that fluoxetine upregulates VGF expression in cortical astrocytes (Fig. 1) are in line with recent findings, demonstrating 
that chronic treatment with fluoxetine increases VGF mRNA levels in the rat hippocampus and prefrontal cortex (Cattaneo et al. 2010). However, to our knowledge, this is the first observation of an upregulation of VGF expression by an antidepressant in non-neuronal cells. Upregulation of VGF expression by fluoxetine in cortical astrocytes may be mediated by BDNF, as we found that fluoxetine increases BDNF expression (Fig. 1), and it has been shown that BDNF induces VGF expression (Bonni et al. 1995).

The roles of VGF in depression and antidepressant actions (Thakker-Varia and Alder 2009; Malberg and Monteggia 2008) suggest that the upregulation of VGF expression by fluoxetine in astrocytes may contribute to its antidepressant actions.

Astrocytes play an essential role in brain energy metabolism by providing energy substrates for neurons (Magistretti 2008). Although glucose is the obligatory energy substrate for the brain under normal resting conditions, there is increasing evidence that lactate released by astrocytes can be used by neurons to sustain their synaptic activity (Rouach et al. 2008; Pellerin et al. 2007). Lactate is an energy substrate that preserves neuronal function in experimental models of excitotoxicity (Maus et al. 1999), posthypoxic recovery (Schurr et al. 1997a, b), cerebral ischemia (Schurr et al. 1997b), and energy deprivation (Cater et al. 2001), highlighting the importance of astrocyte-derived lactate for neuronal function and viability.

In unmedicated subjects with familial major depressive disorder, glucose metabolism is reduced in the dorsomedial/dorsal anterolateral prefrontal cortex and subgenual prefrontal cortex (Drevets 2000b, 2001), while treatment with fluoxetine normalizes the frontal hypometabolism (Mayberg et al. 2000). These observations suggest that the increased release of lactate by cortical astrocytes in response to fluoxetine (Fig. 3a) may contribute to protect neurons from the damaging effects of stress, a critical factor in the etiology of depression, and to normalize the hypometabolism in the prefrontal cortex of depressed patients.

Among other energy substrates that support energydependent processes in the brain, glycogen, which is found primarily in astrocytes (Magistretti et al. 1993), provides an important energy source during periods of increased energy demand when glucose supply is not sufficient to meet the transient elevation in energy requirements (Brown and Ransom 2007). Glycogenolysis is particularly well suited to rapidly provide large amounts of glycolytically derived energy because, in contrast to glycolysis, it does not require ATP expenditure to phosphorylate glucose, and breakdown of glycogen to pyruvate produces more energy than the formation of pyruvate from glucose. Astrocyte glycogen can be metabolized to lactate which is exported to the extracellular space and taken up by neurons to be used as an aerobic substrate (Brown and Ransom 2007). These observations suggest that the increased release of lactate by fluoxetine in cortical astrocytes (Fig. 3a) may result not only from the stimulation of glucose utilization (Fig. 3b), but also from the degradation of glycogen (Fig. 3c). Glycogen degradation to lactate and transfer of lactate from astrocytes to neurons may be required to support the increased energy demand associated with the neurotrophic effects induced by fluoxetine through BDNF, VEGF, and VGF.

Recent data show that glycogen plays an important role in sustaining glutamatergic neurotransmission (Sickmann et al. 2009). In particular, energy derived from glycogen breakdown was demonstrated to be necessary for the maintenance of sodium-dependent glutamate transport capacity in astrocytes (Sickmann et al. 2009). Interestingly, accumulating evidence suggests the existence of abnormalities in the glutamatergic system of patients with major depressive disorder. For example, elevated levels of glutamate were measured in the occipital cortex of individuals diagnosed with major depressive disorder (Sanacora et al. 2004) and in post-mortem frontal cortex from patients with major depression (Hashimoto et al. 2007). These observations suggest that stimulation of glycogenolysis by fluoxetine may contribute to provide enough energy for the enhanced astrocyte glutamate uptake associated with elevated glutamate levels in patients with major depression.

Brain imaging and post-mortem studies have revealed structural alterations in patients with major depressive disorder that result from reductions in neuronal size and decreases in the numbers of neurons and glia in these brain regions (Rajkowska 2000; Rajkowska and Miguel-Hidalgo 2007). Reductions in neuronal size and density may be due, in part, to a decreased ability of astrocytes to provide trophic and metabolic support to neurons. Results of this study suggest that, by increasing the expression of specific astrocyte-derived neurotrophic/growth factors and lactate release from astrocytes, fluoxetine may contribute to normalize the trophic and metabolic support to neurons in major depression. In contrast, the tricyclic antidepressants desipramine and imipramine do not regulate the expression of neurotrophic/growth factors and glucose metabolism in astrocytes, suggesting that the therapeutic effects of desipramine and imipramine are not mediated by this glial cell population or involve other astrocytic mechanisms that remain to be elucidated.

Acknowledgments The authors are grateful to Cendrine Barrière Borgioni and Evelyne Ruchti for valuable technical assistance. This work was supported by the Swiss National Science Foundation grants 31003A-124783 (to JLM) and 3100AO-108336/1 (to PJM), the Désirée and Niels Yde's Foundation (to JLM and PJM), and the 
Swiss Academy of Medical Sciences (to JLM and PJM). The authors have no financial relationship with the Swiss National Science Foundation, the Désirée and Niels Yde's Foundation, and the Swiss Academy of Medical Sciences. All experiments comply with the Swiss federal act on animal protection and the Swiss animal protection ordinance.

\section{References}

Alder J, Thakker-Varia S, Bangasser DA, Kuroiwa M, Plummer MR, Shors TJ, Black IB (2003) Brain-derived neurotrophic factorinduced gene expression reveals novel actions of VGF in hippocampal synaptic plasticity. J Neurosci 23:10800-10808

Allaman I, Gavillet M, Belanger M, Laroche T, Viertl D, Lashuel HA, Magistretti PJ (2010) Amyloid-beta aggregates cause alterations of astrocytic metabolic phenotype: impact on neuronal viability. J Neurosci 30:3326-3338

Allaman I, Pellerin L, Magistretti PJ (2004) Glucocorticoids modulate neurotransmitter-induced glycogen metabolism in cultured cortical astrocytes. J Neurochem 88:900-908

Allen NJ, Barres BA (2005) Signaling between glia and neurons: focus on synaptic plasticity. Curr Opin Neurobiol 15:542-548

Banasr M, Duman RS (2008) Glial loss in the prefrontal cortex is sufficient to induce depressive-like behaviors. Biol Psychiatry 64:863-870

Barker AJ, Ullian EM (2010) Astrocytes and synaptic plasticity. Neuroscientist 16:40-50

Berton O, Nestler EJ (2006) New approaches to antidepressant drug discovery: beyond monoamines. Nat Rev Neurosci 7:137-151

Bianchi MT (2008) Non-serotonin anti-depressant actions: direct ion channel modulation by SSRIs and the concept of single agent poly-pharmacy. Med Hypotheses 70:951-956

Bolo NR, Hode Y, Nedelec JF, Laine E, Wagner G, Macher JP (2000) Brain pharmacokinetics and tissue distribution in vivo of fluvoxamine and fluoxetine by fluorine magnetic resonance spectroscopy. Neuropsychopharmacology 23:428-438

Bonni A, Ginty DD, Dudek H, Greenberg ME (1995) Serine 133phosphorylated CREB induces transcription via a cooperative mechanism that may confer specificity to neurotrophin signals. Mol Cell Neurosci 6:168-183

Bremner JD, Vythilingam M, Vermetten E, Nazeer A, Adil J, Khan S, Staib LH, Charney DS (2002) Reduced volume of orbitofrontal cortex in major depression. Biol Psychiatry 51:273-279

Brown AM, Ransom BR (2007) Astrocyte glycogen and brain energy metabolism. Glia 55:1263-1271

Cater HL, Benham CD, Sundstrom LE (2001) Neuroprotective role of monocarboxylate transport during glucose deprivation in slice cultures of rat hippocampus. J Physiol 531:459-466

Cattaneo A, Sesta A, Calabrese F, Nielsen G, Riva MA, Gennarelli M (2010) The expression of VGF is reduced in leukocytes of depressed patients and it is restored by effective antidepressant treatment. Neuropsychopharmacology 35:1423-1428

Chen B, Dowlatshahi D, MacQueen GM, Wang JF, Young LT (2001) Increased hippocampal BDNF immunoreactivity in subjects treated with antidepressant medication. Biol Psychiatry 50:260-265

Choudary PV, Molnar M, Evans SJ, Tomita H, Li JZ, Vawter MP, Myers RM, Bunney WE Jr, Akil H, Watson SJ, Jones EG (2005) Altered cortical glutamatergic and GABAergic signal transmission with glial involvement in depression. Proc Natl Acad Sci USA 102:15653-15658

Cotter D, Mackay D, Chana G, Beasley C, Landau S, Everall IP (2002) Reduced neuronal size and glial cell density in area 9 of the dorsolateral prefrontal cortex in subjects with major depressive disorder. Cereb Cortex 12:386-394
Czeh B, Simon M, Schmelting B, Hiemke C, Fuchs E (2006) Astroglial plasticity in the hippocampus is affected by chronic psychosocial stress and concomitant fluoxetine treatment. Neuropsychopharmacology 31:1616-1626

Drevets WC (2000a) Functional anatomical abnormalities in limbic and prefrontal cortical structures in major depression. Prog Brain Res 126:413-431

Drevets WC (2000b) Neuroimaging studies of mood disorders. Biol Psychiatry 48:813-829

Drevets WC (2001) Neuroimaging and neuropathological studies of depression: implications for the cognitive-emotional features of mood disorders. Curr Opin Neurobiol 11:240-249

Dwivedi Y, Rizavi HS, Conley RR, Roberts RC, Tamminga CA, Pandey GN (2003) Altered gene expression of brain-derived neurotrophic factor and receptor tyrosine kinase B in postmortem brain of suicide subjects. Arch Gen Psychiatry 60:804-815

Ferrara N, Gerber HP, LeCouter J (2003) The biology of VEGF and its receptors. Nat Med 9:669-676

Furutani K, Ohno Y, Inanobe A, Hibino H, Kurachi Y (2009) Mutational and in silico analyses for antidepressant block of astroglial inward-rectifier Kir4.1 channel. Mol Pharmacol 75:1287-1295

Ghosh A, Carnahan J, Greenberg ME (1994) Requirement for BDNF in activity-dependent survival of cortical neurons. Science 263:1618-1623

Greene J, Banasr M, Lee B, Warner-Schmidt J, Duman RS (2009) Vascular endothelial growth factor signaling is required for the behavioral actions of antidepressant treatment: pharmacological and cellular characterization. Neuropsychopharmacology 34:2459-2468

Guo S, Arai K, Stins MF, Chuang DM, Lo EH (2009) Lithium upregulates vascular endothelial growth factor in brain endothelial cells and astrocytes. Stroke 40:652-655

Halassa MM, Haydon PG (2010) Integrated brain circuits: astrocytic networks modulate neuronal activity and behavior. Annu Rev Physiol 72:335-355

Hashimoto K, Sawa A, Iyo M (2007) Increased levels of glutamate in brains from patients with mood disorders. Biol Psychiatry 62:1310-1316

Henry ME, Schmidt ME, Hennen J, Villafuerte RA, Butman ML, Tran P, Kerner LT, Cohen B, Renshaw PF (2005) A comparison of brain and serum pharmacokinetics of R-fluoxetine and racemic fluoxetine: a 19-F MRS study. Neuropsychopharmacology 30:1576-1583

Hisaoka K, Takebayashi M, Tsuchioka M, Maeda N, Nakata Y, Yamawaki S (2007) Antidepressants increase glial cell linederived neurotrophic factor production through monoamineindependent activation of protein tyrosine kinase and extracellular signal-regulated kinase in glial cells. J Pharmacol Exp Ther 321:148-157

Hoshaw BA, Malberg JE, Lucki I (2005) Central administration of IGF-I and BDNF leads to long-lasting antidepressant-like effects. Brain Res 1037:204-208

Hunsberger JG, Newton SS, Bennett AH, Duman CH, Russell DS, Salton SR, Duman RS (2007) Antidepressant actions of the exercise-regulated gene VGF. Nat Med 13:1476-1482

Jin K, Mao XO, Greenberg DA (2006) Vascular endothelial growth factor stimulates neurite outgrowth from cerebral cortical neurons via Rho kinase signaling. J Neurobiol 66:236-242

Jin K, Zhu Y, Sun Y, Mao XO, Xie L, Greenberg DA (2002) Vascular endothelial growth factor (VEGF) stimulates neurogenesis in vitro and in vivo. Proc Natl Acad Sci USA 99:11946-11950

Jones KR, Farinas I, Backus C, Reichardt LF (1994) Targeted disruption of the BDNF gene perturbs brain and sensory neuron development but not motor neuron development. Cell 76:989_ 999 
Khaibullina AA, Rosenstein JM, Krum JM (2004) Vascular endothelial growth factor promotes neurite maturation in primary CNS neuronal cultures. Brain Res Dev Brain Res 148:59-68

Khawaja X, Xu J, Liang JJ, Barrett JE (2004) Proteomic analysis of protein changes developing in rat hippocampus after chronic antidepressant treatment: implications for depressive disorders and future therapies. J Neurosci Res 75:451-460

Krum JM, Mani N, Rosenstein JM (2002) Angiogenic and astroglial responses to vascular endothelial growth factor administration in adult rat brain. Neuroscience 110:589-604

Lewin GR, Barde YA (1996) Physiology of the neurotrophins. Annu Rev Neurosci 19:289-317

Lindholm D, Carroll P, Tzimagiogis G, Thoenen H (1996) Autocrineparacrine regulation of hippocampal neuron survival by IGF-1 and the neurotrophins BDNF, NT-3 and NT-4. Eur J Neurosci 8:1452-1460

Livak KJ, Schmittgen TD (2001) Analysis of relative gene expression data using real-time quantitative PCR and the 2(-Delta Delta C (T)) Method. Methods 25:402-408

Magistretti PJ (2008) Brain energy metabolism. In: Squire LR, Berg D, Bloom FE, Du Lac S, Ghosh A, Spitzer NC (eds) Fundamental neuroscience, 3rd edn. Academic Press, San Diego, pp 271-293

Magistretti PJ, Manthorpe M, Bloom FE, Varon S (1983) Functional receptors for vasoactive intestinal polypeptide in cultured astroglia from neonatal rat brain. Regul Pept 6:71-80

Magistretti PJ, Sorg O, Martin JL (1993) Regulation of glycogen metabolism in astrocytes: physiological, pharmacological, and pathological aspects. In: Murphy S (ed) Astrocytes: pharmacology and function. Academic Press, San Diego, pp 243-265

Malberg JE, Monteggia LM (2008) VGF, a new player in antidepressant action? Sci Signal 1:e19

Mallei A, Shi B, Mocchetti I (2002) Antidepressant treatments induce the expression of basic fibroblast growth factor in cortical and hippocampal neurons. Mol Pharmacol 61:1017-1024

Maus M, Marin P, Israel M, Glowinski J, Premont J (1999) Pyruvate and lactate protect striatal neurons against N-methyl-D-aspartateinduced neurotoxicity. Eur J Neurosci 11:3215-3224

Mayberg HS, Brannan SK, Tekell JL, Silva JA, Mahurin RK, McGinnis S, Jerabek PA (2000) Regional metabolic effects of fluoxetine in major depression: serial changes and relationship to clinical response. Biol Psychiatry 48:830-843

McAllister AK, Katz LC, Lo DC (1996) Neurotrophin regulation of cortical dendritic growth requires activity. Neuron 17:1057-1064

McAllister AK, Lo DC, Katz LC (1995) Neurotrophins regulate dendritic growth in developing visual cortex. Neuron 15:791-803

Newton SS, Collier EF, Hunsberger J, Adams D, Terwilliger R, Selvanayagam E, Duman RS (2003) Gene profile of electroconvulsive seizures: induction of neurotrophic and angiogenic factors. J Neurosci 23:10841-10851

Nibuya M, Morinobu S, Duman RS (1995) Regulation of BDNF and trkB mRNA in rat brain by chronic electroconvulsive seizure and antidepressant drug treatments. J Neurosci 15:7539-7547

Ongur D, Drevets WC, Price JL (1998) Glial reduction in the subgenual prefrontal cortex in mood disorders. Proc Natl Acad Sci USA 95:13290-13295

Pellerin L, Bouzier-Sore AK, Aubert A, Serres S, Merle M, Costalat R, Magistretti PJ (2007) Activity-dependent regulation of energy metabolism by astrocytes: An update. Glia 55:1251-1262

Perea G, Navarrete M, Araque A (2009) Tripartite synapses: astrocytes process and control synaptic information. Trends Neurosci 32:421-431

Rajkowska G (2000) Postmortem studies in mood disorders indicate altered numbers of neurons and glial cells. Biol Psychiatry 48:766-777

Rajkowska G, Miguel-Hidalgo JJ (2007) Gliogenesis and glial pathology in depression. CNS Neurol Disord Drug Targets 6:219-233

Rajkowska G, Miguel-Hidalgo JJ, Wei J, Dilley G, Pittman SD, Meltzer HY, Overholser JC, Roth BL, Stockmeier CA (1999)
Morphometric evidence for neuronal and glial prefrontal cell pathology in major depression. Biol Psychiatry 45:1085-1098

Rosenstein JM, Mani N, Khaibullina A, Krum JM (2003) Neurotrophic effects of vascular endothelial growth factor on organotypic cortical explants and primary cortical neurons. J Neurosci 23:11036-11044

Rouach N, Koulakoff A, Abudara V, Willecke K, Giaume C (2008) Astroglial metabolic networks sustain hippocampal synaptic transmission. Science 322:1551-1555

Salton SR, Ferri GL, Hahm S, Snyder SE, Wilson AJ, Possenti R, Levi A (2000) VGF: a novel role for this neuronal and neuroendocrine polypeptide in the regulation of energy balance. Front Neuroendocrinol 21:199-219

Sanacora G, Gueorguieva R, Epperson CN, Wu YT, Appel M, Rothman DL, Krystal JH, Mason GF (2004) Subtype-specific alterations of gamma-aminobutyric acid and glutamate in patients with major depression. Arch Gen Psychiatry 61:705-713

Schurr A, Payne RS, Miller JJ, Rigor BM (1997a) Brain lactate is an obligatory aerobic energy substrate for functional recovery after hypoxia: further in vitro validation. J Neurochem 69:423-426

Schurr A, Payne RS, Miller JJ, Rigor BM (1997b) Glia are the main source of lactate utilized by neurons for recovery of function posthypoxia. Brain Res 774:221-224

Sheline YI (2003) Neuroimaging studies of mood disorder effects on the brain. Biol Psychiatry 54:338-352

Shirayama Y, Chen AC, Nakagawa S, Russell DS, Duman RS (2002) Brain-derived neurotrophic factor produces antidepressant effects in behavioral models of depression. J Neurosci 22:3251-3261

Si X, Miguel-Hidalgo JJ, O'Dwyer G, Stockmeier CA, Rajkowska G (2004) Age-dependent reductions in the level of glial fibrillary acidic protein in the prefrontal cortex in major depression. Neuropsychopharmacology 29:2088-2096

Sickmann HM, Walls AB, Schousboe A, Bouman SD, Waagepetersen HS (2009) Functional significance of brain glycogen in sustaining glutamatergic neurotransmission. J Neurochem 109(Suppl 1):80-86

Slezak M, Pfrieger FW (2003) New roles for astrocytes: regulation of CNS synaptogenesis. Trends Neurosci 26:531-535

Thakker-Varia S, Alder J (2009) Neuropeptides in depression: role of VGF. Behav Brain Res 197:262-278

Thakker-Varia S, Krol JJ, Nettleton J, Bilimoria PM, Bangasser DA, Shors TJ, Black IB, Alder J (2007) The neuropeptide VGF produces antidepressant-like behavioral effects and enhances proliferation in the hippocampus. J Neurosci 27:12156-12167

Turner CA, Gula EL, Taylor LP, Watson SJ, Akil H (2008) Antidepressant-like effects of intracerebroventricular FGF2 in rats. Brain Res 1224:63-68

Wada T, Haigh JJ, Ema M, Hitoshi S, Chaddah R, Rossant J, Nagy A, van der Kooy D (2006) Vascular endothelial growth factor directly inhibits primitive neural stem cell survival but promotes definitive neural stem cell survival. J Neurosci 26:6803-6812

Wang DD, Bordey A (2008) The astrocyte odyssey. Prog Neurobiol $86: 342-367$

Warner-Schmidt JL, Duman RS (2007) VEGF is an essential mediator of the neurogenic and behavioral actions of antidepressants. Proc Natl Acad Sci USA 104:4647-4652

Warner-Schmidt JL, Duman RS (2008) VEGF as a potential target for therapeutic intervention in depression. Curr Opin Pharmacol 8:14-19

Wong DT, Perry KW, Bymaster FP (2005) Case history: the discovery of fluoxetine hydrochloride (Prozac). Nat Rev Drug Discov 4:764-774

Wong ML, Licinio J (2004) From monoamines to genomic targets: a paradigm shift for drug discovery in depression. Nat Rev Drug Discov 3:136-151

Zhang X, Peng L, Chen Y, Hertz L (1993) Stimulation of glycogenolysis in astrocytes by fluoxetine, an antidepressant acting like 5-HT. NeuroReport 4:1235-1238 